\title{
Methodology of complex evaluation of energy transportation systems from remote renewable resources
}

\author{
Oleg Baldynov $^{1 *}$, Sergei Popov ${ }^{1}$ \\ ${ }^{1}$ Melentiev Energy Systems Institute Siberian Branch of the Russian Academy of Sciences Irkutsk, Russian Federation
}

\begin{abstract}
In the last two decades, the unit cost of so-called "new" renewable energy sources has shown a significant decline: photovoltaic panels and wind turbine generators, which is the main reason for the increase in the share of RES in primary energy consumption. However, regions with suitable natural and climatic conditions for the development of renewable energy aren't in a generally densely populated and located at a significant geographical distance from the centers of energy consumption (the level of solar insolation in the Gobi and Atacama deserts, wind speed on the coasts of the Arctic Ocean and the Pacific Oceans, etc.). Anticipating a significant development of the need for the use of renewable energy, it is necessary to perform preliminarily a complex of evaluation of energy transportation systems from remote renewable resources.
\end{abstract}

\section{Introduction}

The main problems with the use of renewable energy sources (RES) are the stochastic mode of electricity generation at solar photovoltaic (PV) and wind (WPP) power plants (the most common sources of renewable energy) and their low capacity factor (Fig. 1.).

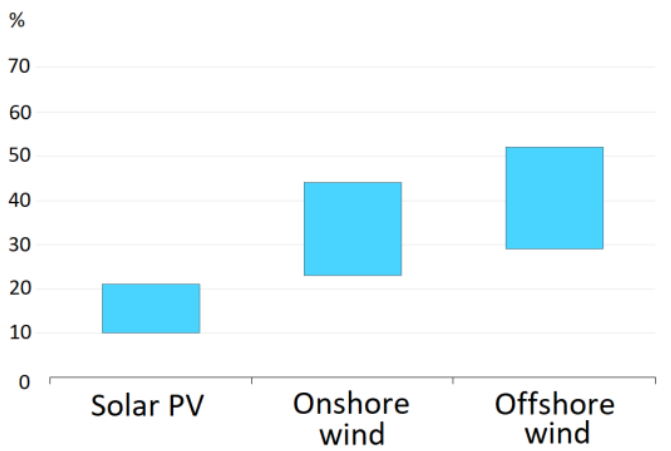

Fig. 1. Typical capacity factor of solar PV, onshore and offshore wind stations

These problems, along with the capacity constraints of the power networks, will lead to low economic efficiency of the construction of electric power transmission lines from RES locations to energy consumption centers due to the underutilization of such power lines and high levels of capital expenditure. The solutions to this problem can be the combined use of RES capacities with other sources of generation (nuclear power plants, thermal power station, hydroelectric power plants, etc.), as well as the use of energy storage systems (ESS). These include pumped-storage hydroelectricity and Compressed-air energy storage plants (PSH and CAES), network accumulation batteries, superconducting magnetic energy storage (SMES), etc. [1]. To date, the most common ESS are $\mathrm{PSH}$ and accumulation batteries (AB). According to [2], more than $98 \%$ of the installed storage capacity in the world is accounted for by pumped-storage hydroelectricity plants. However, the mass use of the PSH is limited, firstly, by the need for a suitable terrain or geological structures, since the construction of the station requires a height difference, and secondly, the energy reserve of the PSH depends on the volume of reservoirs, which can lead to flooding of a large area of the territory under use.

Today according to the IEA the total capacity of network $\mathrm{AB}$ is about $4 \mathrm{GW}$ and continues to grow along with reduction in the cost of this technology [3]. The use of $\mathrm{AB}$ systems is suitable for hourly / daily energy storage, so while the generation of renewable energy can be stopped for quite long periods, consequently leads to the need to increase the capacity of the AB. A lithiumion battery pack with a storage capacity of $1 \mathrm{kWh}$ requires $0.3 \mathrm{~kg}$ of lithium [4]. Expanding the use of these batteries can lead to the exhaustion of easily accessible reserves of lithium, and as a result, to an increase in the cost of batteries with its use.

\section{Energies transportation systems from remote renewable resources}

An alternative solution may be development of infrastructure based on the concept of "Power to X" (P2X), which involves using electricity for production of secondary energy carriers. These systems include a set of complexes for the producing, transporting, distributing, and using energy resources derived from

* Corresponding author: oabaldynov@isem.irk.ru 
electricity generated by renewable sources. Consider existing studies on this topic:

- Assessment of the effectiveness of the involvement of non-traditional renewable energy sources in the energy balance of the region [5]. The methodology covers the social, technological, economic, and energy aspects of renewable energy production. At the same time, the system of energy transportation from the energy source to the consumer is not evaluated;

- Liquid Organic Hydrogen Carriers and alternatives for international transport of renewable hydrogen [6] this study presents a technical and economic assessment (comparison of transport and chain efficiency, levelised cost of energy (LCOE)) of liquid organic hydrogen carriers (dibenzyltoluene, methanol, N-ethylcarbazole, methylcyclohexane $(\mathrm{MCH})$ - further united by the term «hyder» (hydrogen carrier). The received results are compared with the transportation of compressed and liquid hydrogen, as well as with the production of hydrogen at the point of consumption and the transmission of electricity through HVDC lines. Hydrogen is produced by PEM-electrolyzers based on renewable energy. In the study, the amount of energy transported is set, while the optimization of the structural objects of energy production, depending on the climatic conditions, is not performed. Environmental assessment of energy production and transportation is not executed;

- Large-scale production and transport of hydrogen from Norway to Europe and Japan: Value chain analysis and comparison of liquid hydrogen and ammonia as energy carriers [7] - the article deals with comparative cost and environmental assessment of the production of liquefied hydrogen and ammonia with their subsequent transportation from Norway to the places of consumption in Rotterdam and Tokyo. Hydrogen is produced by steam-gas reforming of natural gas (90\%) and electrolysis (10\%) based on renewable energy, after which it is liquefied. The paper focuses on the study of the processes of liquefaction, storage and transportation of hydrogen, considering of the electrolysis hydrogen production is limited by the amount of electricity consumed and economic costs;

- Long-distance renewable hydrogen transmission via cables and pipelines [8] - two systems for transporting renewable energy: an electric hydrogen system in which electricity is transmitted via HVDC and converted to hydrogen for long-term storage on the consumer side, as well as a system for transporting hydrogen through gas pipelines are presented in the study. The aim of the work is to compare LCOE of both systems;

- Bulk power transmission at sea: Life cycle cost comparison of electricity and hydrogen as energy vectors [9] - the aim of this study is to determine the break-even distance at which the transportation of liquid hydrogen ( $\mathrm{LH} 2)$ by sea tankers and gas pipeline $(\mathrm{cH} 2)$ becomes more economic in comparison with electronic energy transmisson by HVDC. The evaluation of the presented systems is carried out by the life cycle analysis method at different energy production costs.

In most of the studies conducted in the field of integration of renewable energy into energy supply systems, the main criteria are the minimum LCOE and the energy efficiency of the entire energy supply chain to the consumers.

\section{Methodology of complex evaluation of energy transportation systems from remote renewable resources}

In our opinion, these criteria are insufficient to compare the energy transportation systems from remote renewable resources. Despite the existing methodologies, we suppose that the issue of energy transportation systems from remote RES is unresolved, since the above assessment systems don't cover all the criteria for a system of long-distance energy transportation from RES to final energy consumers. In addition, the use of such innovative technologies as fuel cells will lead to a radical change in the systems of transportation of renewable energy, and will expand the range of its consuming.

Figures 2 and 3 show long-range renewable energy transportation systems based on the use of such energy carriers as hydrogen, ammonia, synthetic methane and LOHC - methylcyclohexane (see fig. 2. and fig. 3.) 


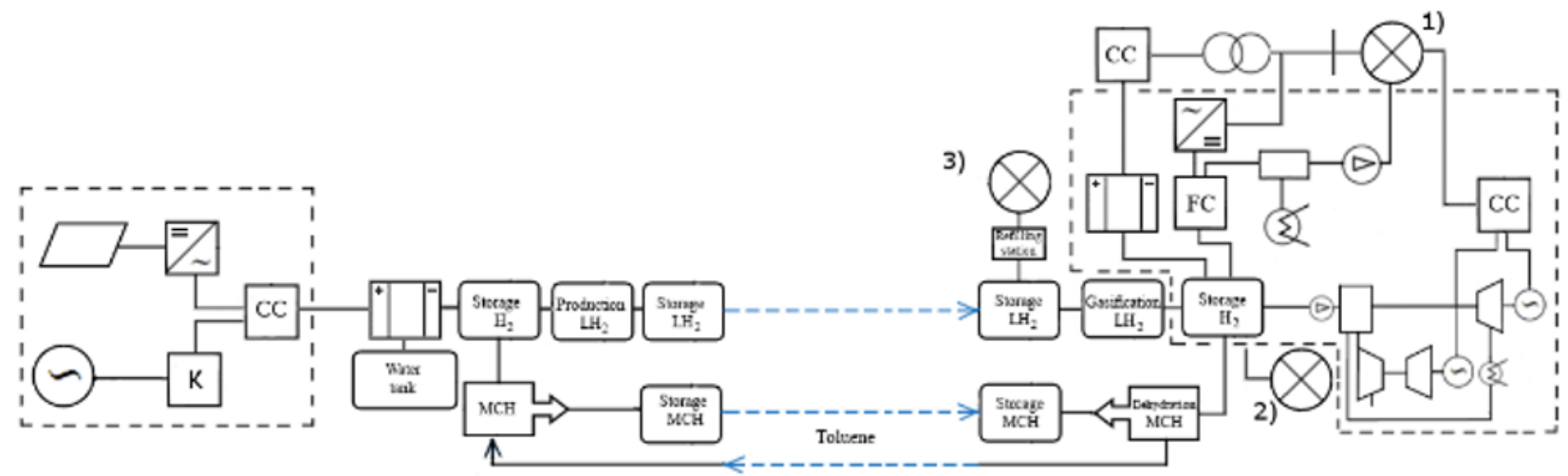

Fig. 2. Energy transportation systems from remote renewable resources: liquefied hydrogen, methylcyclohexane (1industrial consumers, 2 - consumers in the transport sector, 3-consumers in the residential sector)

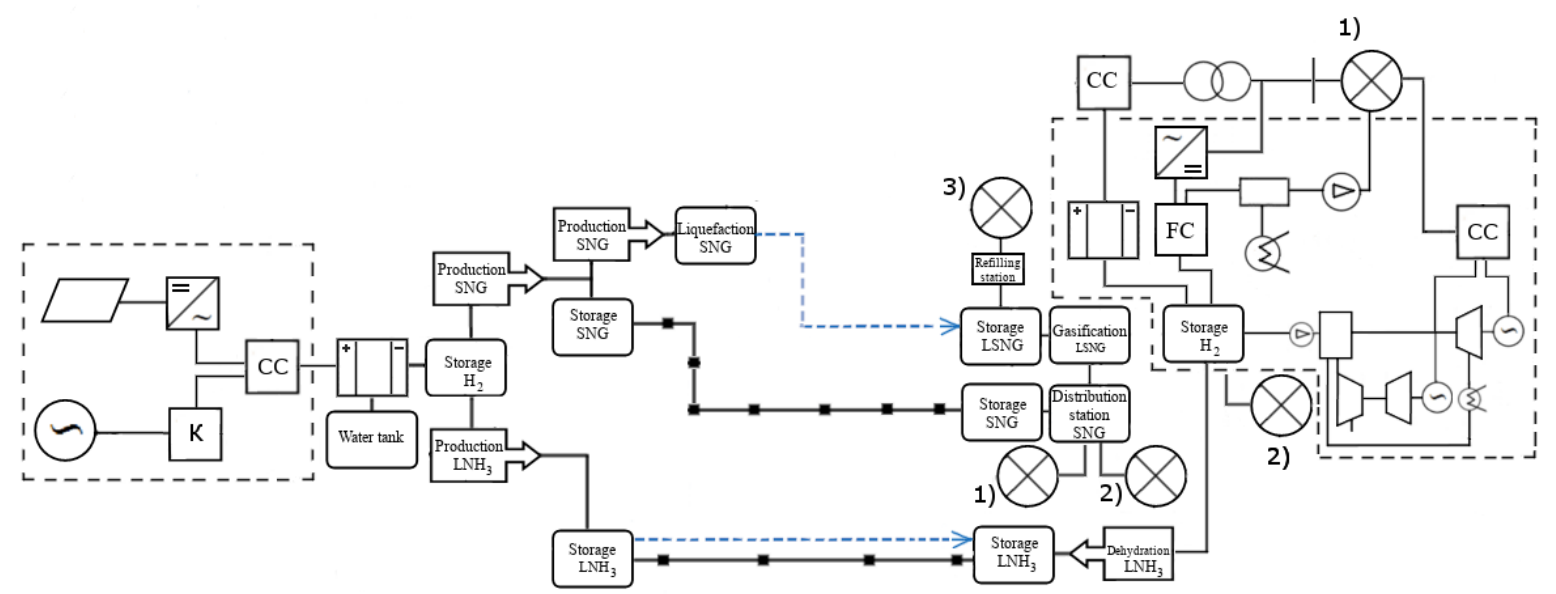

Fig. 3. Energy transportation systems from remote renewable resources: synthetic natural gas, ammonia (1-industrial consumers, 2 - consumers in the transport sector, 3-consumers in the residential sector)

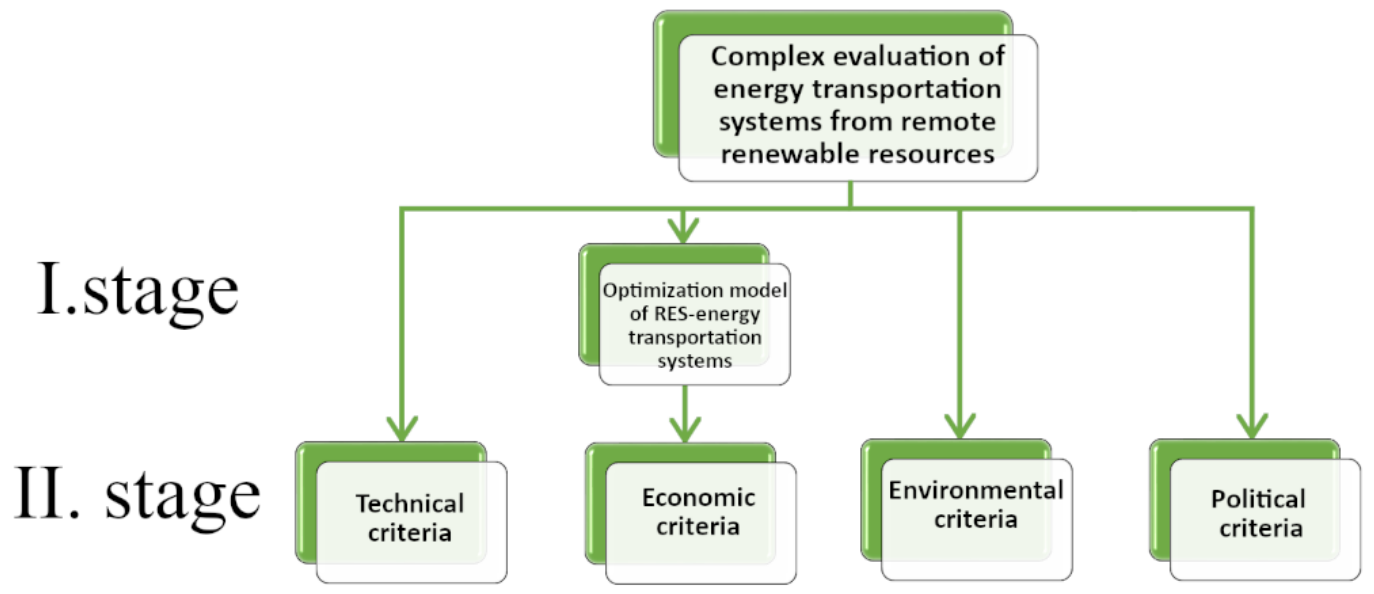

Fig. 4. Complex evaluation of energy transportation systems from remote renewable resources

These energy transportation systems vary significantly in various indicators of energy and economic efficiency, anthropogenic impact on the environment, conditions and requirements of production processes, the degree of acceptance by society, etc.

The creation of infrastructure for a specific energy transportation system from remote RES requires advance and significant amounts of investments, the development of knowledge-intensive industries, the training of highly qualified specialists, the development of quality standards, changes in the nomenclature of industrial production, amendments to existing legislation, the use of investment and tax instruments. As a result, the task arises of preparing a methodological apparatus that allows to choose the most optimal option 
for building energy systems based on the production of renewable energy.

Figure 4 shows an approach to a complex evaluation of energy transportation systems from remote renewable resources, that includes technical, economic, environmental and policy criteria.

From a methodological point of view, the evaluation can be divided into two stages. The first stage uses an optimization mathematical model that describes the functioning of renewable energy transportation systems from the moment of energy production to the use by final energy consumers.

For the considered renewable energy transportation systems (production of methylcyclohexane, liquefied hydrogen, synthetic methane and ammonia), the general main node is the production of hydrogen gas by the electrolysis method, which is converted then into some other hyder. The accumulated compressed hydrogen can be used for the energy supply of the production complex when there is a shortage of electricity generated by RES through the use of fuel cells. If the reserves of compressed hydrogen are insufficient, other hyders produced by $\mathrm{P} 2 \mathrm{X}$ complex are used for energy suppling of structural objects.

Within the framework of this model, it is assumed that the only sources of generation in the production of energy carriers will be PV and wind power station. Since their efficiency depends on the climatic conditions in the area under consideration, the composition of the energy production facilities of the complex depends on the natural and climatic conditions.

The following parameters are set in the model:

1. annual demand and loading schedule of the hyders produced by the complex,

2. climate indicators of the area: wind speed, solar radiation level,

3. parameters of an electric generation of PV and wind stations,

4. the initial state of the system (the initial volume of hyders in the storage tanks),

5. indicators of energy and technological losses,

6. unit levelised costs of services provided by the structural objects of the green energy production complex: reversible solid oxide installations, compressors, compressed hydrogen storage tanks, hyders production plants and their storage tanks,

7. technical (volume of transported energy carriers, fuel consumption per $1000 \mathrm{~km}$ ) and economic parameters (rental cost, or unit cost of construction) of sea tankers, their number, also the distance of transportation of energy carriers to the point of unloading.

The calculated variables of the model: the annual electric generation of PV and wind stations, the composition and dimension of structural objects, the final cost of energy carriers on the consumer side, including transportation costs.

\subsection{Criterias}

Technical, economic, environmental and political criteria are calculated at the second stage based on the data obtained:

Technical criteria: The estimation of energy losses is carried out by comparing the efficiency of the elements of the transportation system from the production of electricity based on renewable energy resources to the final energy consumers. This method allows determining the total amount of technical losses caused by physical processes during the production, preparation for transportation, delivery and distribution, storage and use of energy carriers throughout the energy supply chain from RES to the final consumers.

1.1 From a theoretical point of view, energy loss analysis is the best way to evaluate and compare different energy supply systems. However, in practice, to caring out this analysis is quite difficult, since it is impossible to take into account energy losses due to the infelicities of the accounting system, commercial losses, etc. Nevertheless, by predicting the creation of new energy systems, a step-by-step analysis of energy efficiency allows to determine the volume of losses in each node of the energy transportation system and get numerical values of the total volume of losses of each of the systems and compare them with each other:

$$
\left\{\begin{array}{c}
\eta_{\text {total } 1}=\eta_{\text {pr. } 1} * \eta_{\text {tr. } 1} * \eta_{\text {del. } 1} * \eta_{\text {cons. } 1} \\
\eta_{\text {total } 2}=\eta_{\text {pr. } 2} * \eta_{\text {tr. } 2} * \eta_{\text {del. } 2} * \eta_{\text {cons. } 2} \\
\eta_{\text {total i }}=\eta_{\text {pr. } 1} * \eta_{\text {tr. } .1} * \eta_{\text {del. } .1} * \eta_{\text {cons. } .1}
\end{array}\right.
$$

where

$\eta_{\text {total }}$ - the total level of energy losses of the energy transportation system,

$\eta_{\text {pr. }}$ - energy carrier's production losses,

$\eta_{\text {tr. }}$ - energy carrier's transportation losses,

$\eta_{\text {del. }}-$ delivery networks losses,

$\eta_{\text {cons. }}$ - energy carrier's consume losses.

1.2 EROEI (energy returned on energy invested) the EROEI criterion is the ratio of the energy received to the amount of energy spent on obtaining this energy resource:

$$
\text { EROEI }=\frac{E}{E_{1}+E_{2}+E_{3}},
$$

where

E - energy produced;

$\mathrm{E}_{1}$ - energy costs associated with infrastructure construction and the works of related sectors of the economy;

$\mathrm{E}_{2}$ - energy costs associated with the production work of corresponding energy infrastructure;

$\mathrm{E}_{3}$ - energy costs associated with the liquidation of energy infrastructure facilities.

At the first stage, energy expenses are associated with the need to create an energy infrastructure, that includes consideration of the entire value chain. At the second stage, energy costs are associated with ensuring the current activity of the object. The third stage is related to the energy costs associated with the liquidation activity for the energy facility or system in consideration. 
Economic criteria: The evaluation of the economic efficiency of projects to create energy supply systems from RES includes an assessment of the effectiveness of investment projects and Life-cycle cost analysis.

2.1 The assessment of the effectiveness of investment projects allows assessing the following indicators of the economic efficiency of investments for the creation of energy transportation systems:

Net present value (NPV):

$$
N P V=-I C+\sum_{t=0}^{T} \frac{C F_{t}}{(1+i)^{t}},
$$

where

IC - invest capital,

$C F_{t}$ - cash flow,

$i$ - discount rate,

$t \quad$ - current time period,

$T-$ total number of periods,

Internal rate of return (IRR):

where

$$
\mathrm{IRR}=r_{1}+\frac{N P V_{r_{1}}}{N P V_{r_{1}}-N P V_{r_{2}}} *\left(r_{2}-r_{1}\right)
$$

$r_{1}$ - the value of the discount rate, that $N P V_{r_{1}}>0$

$r_{2}$ - the value of the discount rate, that $N P V_{r_{2}}<0$

Discounted payback period (DPP):

$$
\mathrm{DPP}=\mathrm{n} \text {, that } \sum_{t=0}^{T} \frac{C F_{t}}{(1+i)^{t}}>\mathrm{IC}
$$

After evaluation of the effectiveness of investment projects for each option of creating a power supply system, the corresponding indicators are compared with each other.

2.2 Life-cycle cost analysis (LCCA) allows to determine the cost-effectiveness for each of several alternative systems.

The LCCA involves an assessment of the construction phase of energy supply systems, including the production of materials and equipment for the construction of renewable energy transportation systems; operating costs, including repair works, recovery and recycling of waste and secondary products, depreciation of fixed assets; and the cost of disposal of energy facilities after its useful life:

$$
\begin{aligned}
& \mathrm{LCCA}=C_{\text {пр }}+\sum_{t=1}^{T}\left(I_{t}+\Delta \mathrm{K}_{t}-L_{t}\right) * i, \\
& \text { where }
\end{aligned}
$$

$C_{\text {пр }}-$ construction cost of energy objects,

$I_{t}$ - annual operating costs of the technical system,

$\Delta \mathrm{K}_{t}$ - one-time costs associated with the

commissioning of energy facilities into operation,

$L_{t} \quad$ - liquidation costs of energy objects,

$i$ - discount rate,

$t \quad$ - current time period,

$T \quad-$ useful life of energy objects.

Environmental criteria:

3.1 The amount of greenhouse gas (GHG) emissions is calculated from the stage of production of a particular energy carrier to the stage of final energy consumption:

where

$$
\mathrm{V}_{\text {total }}=\mathrm{V}_{\text {pr. }}+\mathrm{V}_{\text {tr. }}+\mathrm{V}_{\text {del. }}+\mathrm{V}_{\text {cons. }} \text {, }
$$

$V_{\text {total }}$ - total volume of GHG emissions of the energy transportation system,

$V_{\text {pr. }}$ - GHG emissions from energy carrier production,

$V_{\text {tr. }}-$ GHG emissions from energy carrier transportation,

$V_{\text {tr. }}-$ GHG emissions from energy carrier delivery,

$\mathrm{V}_{\text {cons. }}-\mathrm{GHG}$ emissions from energy carrier consume.

GHG emissions during transportation by sea tanker [10]:

$$
\mathrm{V}_{\text {tr. }}=\mathrm{P} * \mathrm{t} * \mathrm{~K}+\frac{\mathrm{V}_{\text {load. }}}{\text { unload. }}
$$

where

$\mathrm{P}$ - engine power (MW)

$t$ - travel time

$\mathrm{K}-\mathrm{GHG}$ emissions coefficients,

$\mathrm{V}_{\frac{\mathrm{n}}{\mathrm{p}}}$ - emissions during loading and unloading.

Political criteria:

Creating energy systems for international energy trade, energy security is an important aspect, since its level indicates the reliability of ensuring consumers ' access to external energy resources. The risks to the country's energy security can be economic (rising energy prices, transportation, etc.), technogenic (system accidents at power lines, pipeline system failures, etc.), and political (the imposition of embargoes and other sanctions).

The complexity of the process of creating the international electric power network "Asian Super Grid" is cited as an example of the importance of political risks. According to the International Renewable Energy Agency (IRENA), the technical potential of wind energy in Mongolia is 2,550 TWh/year, and solar energy is 4,774 TWh/year [11]. This resource potential of renewable energy in Mongolia is of interest to the countries of East Asia: the main transmission lines should unite the electric power grids of the Russian Federation, Mongolia, Japan, China, the Republic of Korea and the Democratic People's Republic of Korea into an international power system. The integration of renewable energy capacity in Mongolia and hydropower capacity in Siberia should ensure the necessary volume of green electricity exports to the countries of East Asia [12].

The creation of the united international power grid (UIPG) will achieve energy and economic benefits: the possibility of cooperation in the construction of large power plants, increased energy security, reducing costs for the construction of reserve capacities, decrease cost of energy for importers, the creation of new jobs, longterm profit generation by exporting countries, increasing the share of renewable energy in final energy consumption, which will positively affect the environmental situation in the region.

Despite these benefits, the creation of a united electric power system has not been realized, including due to political barriers related to the transboundary nature of the power system, and the creation of problems 
in maintaining a high level of energy security for national consumers.

A similar situation occurs with international pipeline systems: countries through which transit pipelines are laid have the opportunity to terminate the transportation of energy carriers, and cause political, social, economic and environmental damage to their partners.

Shipping is less affected, that allows the transport of a large amount of energy along various routes, most of which do not depend on the political regime of any country, and are guided only by recognized international rules. As a result, this type of transportation will be one of the most preferred when creating promising systems for transporting renewable energy over long distances.

\section{Conclusions}

The use of renewable energy in the energy sector increases the level of energy security of the country: according to the energy policy of Japan and the Republic of Korea, the increase in renewable energy capacity is a measure to reduce dependence on energy imports - oil and natural gas. At the same time, both countries stay a course for the development of renewable energy and related hydrogen energy. Their national governments have declared the need to import green hydrogen due to the lack of domestic renewable energy resources.

For exporting countries to enter the international green energy market, it is necessary not only to build up renewable energy capacities, but also to create systems for transporting green energy to consumption centers both abroad and within the country.

The developed methodology a complex evaluation will allow use its to the specific conditions of the selected region in order to determine the optimal way to build the energy infrastructure for renewable energy transportation to remote consumers.

The research was carried out under State Assignment Project (no. FWEU-2021-0004) of the Fundamental Research Program of Russian Federation 2021-2025

\section{References}

1. N.I. Voropai, S.V. Podkovalnikov, V.V. Trufanov, L.S. Belyaev, E.V. Galperova, A.V. Domyshev, et al. In N.I. Voropai (eds.) Substantiation of the development of power systems: Methodology, models, methods, and their application. Novosibirsk, Nauka (2015)

2. United States Department of energy: Energy Storage Technology and Cost Characterization Report (2019) URL: https://www.energy.gov/sites/prod/files/2019/07/f6 5/Storage $\% 20$ Cost $\% 20$ and $\% 20$ Performance $\% 20 \mathrm{Ch}$ aracterization\%20Report_Final.pdf.

3. International energy agency: Battery storage is (almost) ready to play the flexibility game (2019) URL: https://www.iea.org/commentaries/battery- storage-is-almost-ready-to-play-the-flexibilitygame

4. J. L. Aprea, J. C. Bolcich The energy transition towards hydrogen utilization for green life and sustainable human development in Patagonia (2020) https://doi.org/10.1016/j.ijhydene.2020.01.246

5. P.Yu. Buchatskiy, V.S. Simankov Efficiency assessment of involvement of nonconventional renewable energy sources in energy balance of the region (The Bulletin of the Adyghe State University 2012)

6. M. Niermann, S. Timmerberg, S. Drünert, M. Kaltschmitt Liquid Organic Hydrogen Carriers and alternatives for international transport of renewable hydrogen (Renewable and Sustainable Energy Reviews,Vol. 135, 2021) https://doi.org/10.1016/j.rser.2020.110171

7. Y. Ishimoto, M. Voldsund, P. Nekså, S. Roussanaly, D. Berstad, S. Osk Gardarsdottir Large-scale production and transport of hydrogen from Norway to Europe and Japan: Value chain analysis and comparison of liquid hydrogen and ammonia as energy carriers (International journal of hydrogen energy, Vol. 45, Issue 58, 2020, P. 32865-32883) https://doi.org/10.1016/j.ijhydene.2020.09.017

8. Bin Miao, L. Giordano, Siew Hwa Chan Longdistance renewable hydrogen transmission via cables and pipelines (International journal of hydrogen energy,

Vol. 46, Issue 36, 2021, P. 18699-18718) https://doi.org/10.1016/j.ijhydene.2021.03.067

9. R. d'Amore-Domenech, T. J. Leoa, B. G. Pollet Bulk power transmission at sea: Life cycle cost comparison of electricity and hydrogen as energy vectors (Applied energy, Vol. 288, 2021)

10. L. E. Ametistova, A. Yu. Knizhnikov Environmental Aspects of Arctic LNG Projects Development (2016)

11. International renewable energy agency Mongolia renewables readiness assessment (2016)

12. S. Mano, B. Ovgor, Z. Samadov, M. Pudlik, V. Jülch, D. Sokolov, Jae Young Yoon Gobitec and Asian super grid for renewable energies in Northeast Asia (2014) 